\title{
Fundamentos do lugar: uma análise da obra de Cônego Trindade
}

\author{
Eduardo Gusmão de Quadros*
}

\begin{abstract}
Resumo: O livro Lugares e pessoas, escrito por José Trindade da Fonseca e Silva, apesar de ter sidb lançadb há quase sessenta anos, continua sendb a grande dora de síntese sobre a história da Igreja em Goiás. Neste artigo, realizamos uma análise historiográfica dessa obra, apontando camo o conhecimento histórico produzido serviu de plataforma para os combates eclesiásticos vividbs pelo autor.
\end{abstract}

Palavras-chave: Igreja; historiografia; ciência; seaularização; fé.

\begin{abstract}
Há prazer de estar num barco batido pela tempestade, quando se está certo de que ele não perecerá. As perseguições que trabalham a Igreja são dessa natureza. A história da Igreja deve ser propriamente chamada história da Verdade. PASCAL, 1946, p. 172)
\end{abstract}

Será que quem gosta de estudar religiões gosta também de viajar? Por minha parte, responderia afirmativamente. Não qualquer tipo de viagem, certamente. Aquela na qual entramos em um avião, sobrevoamos rapidamente as cidades, ao descer corremos para o hotel e prosseguimos atolados de compromissos, tem pouca serventia. Falamos de viajar passeando, observando, admirando os detalhes, aproveitando as oportunidades para conhecer novos lugares e pessoas.

Esse foi o título colocado por José Trindade da Fonseca e Silva em seu livro: Lugares e pessoas: subsídios eclesiásticos para a história de Goiás. Parece curioso, não? Mas o título nos parece bem escolhido. Revela uma intenção que perpassa a obra. Registrar as pessoas: aquelas importantes, que edificaram o Estado;

* Doutor em História na UnB e professor do Departamento de História da Universidade Estadual de Goiás - UnU Cora Coralina. E-mail: eg.quadros@brturbo.com.br descrever os lugares: toda a rede espacial na qual essas pessoas trabalharam e deixaram sua marca.

O título aponta para uma concepção do conhecimento histórico que trazia obrigações extracientíficas ao historiador. Este deveria contribuir para o incremento do espírito cívico e o amor pátrio. Os heróis apresentados, pilares da nação, serviam para despertar esses sentimentos, indo além da simples razão. Isso, obviamente, sem desfazer ou desconsiderar a verdade dos fatos. Tal corrente historiográfica defendia que, se não estimulasse o sentimento patriótico, o livro de história seria inútil. ${ }^{1}$

Mas sendo o autor um padre, sua vocação pessoal leva-o a trabalhar com a história também para incentivar o amor à Igreja. Encontramos em suas análises, portanto, concepções teológicas mescladas com a tentativa de fazer uma história metodicamente objetiva. Neste artigo, buscamos evidenciar como Cônego Trindade

1. No prefácio de um manual escolar que redigiu, Ernest Lavisse escreve que "se o aluno não levar consigo a viva recordação das nossas glórias nacionais, se não souber que seus antepassados combateram em mil campos de batalha por nobres causas, [..] se não se tornar um cidadão penetrado dos seus deveres e um soldado que ama seu fuzil, o professor terá perdido o seu tempo" (apud Bourdé e Martin, 1990, p. 110). 
operou com essas categorias cognitivas, nesta que é, ainda hoje, a grande obra de síntese tratando da história da Igreja em Goiás.

\section{Um saber militante}

Talvez tenhamos exagerado na avaliação inicial. Cônego Trindade não considerava sua obra um grande livro de história. Seria mais um ensaio (Silva, 1948, p. 21), uma tentativa de suprir a ausência de conhecimento acerca da Igreja goiana. Sem maiores pretensões, chamaa também de crônica (1948, p. 304). Assim ela aparece na maioria de suas páginas. Como crônica, encontramos boas doses de narrativa, de acontecimentos encadeados e notícias dos personagens que fizeram a história de Goiás. A seu ver, não conseguiria fazer uma análise aprofundada com os poucos dados que tinha. Além disso, seu objetivo era construir um roteiro básico, traçar uma espécie de mapa, não estudar temas específicos ou investigar problemas históricos. Por isso, apesar de ele não utilisar o termo, o modelo do livro é ainda o modo redacional dos anais. O livro de Alencastre (1979) é o exemplo maior na historiografia goiana. Essa forma de escrever a história provém, entretanto, da cultura clássica latina: os Anais redigidos por Tácito, "autor modelo" durante muitos séculos (cf. Hartog, 2001). Trindade aproxima-se bastante desse gênero historiográfico, em particular quando aborda o trabalho dos bispos no território goiano.

Mesmo sem considerar seu livro uma investigação histórica de fôlego, o autor fez um grande esforço de pesquisa junto aos arquivos. A autocomplacência do sacerdote não deve nos enganar. Ele pesquisou como os grandes historiadores. Viajou por São Paulo, Rio de Janeiro, Minas Gerais, buscando copilar documentação, além de ter percorrido as inúmeras paróquias de Goiás. O que não conseguiu nessas viagens, pedia por correspondência aos amigos. O resultado pode ser conferido pelo número de fontes inéditas que utilizou, tendo transcrito muitas delas.

Este esforço histórico tinha um motivo imediato. Lugares e pessoas era uma das homenagens ao jubileu episcopal de d. Emanuel. Parece-nos que o livro, por sinal, não chegaria a incluir a história desse último episcopado. Uma outra obra, específica, seria lançada com a Poliantea, publicada igualmente no ano de 1948. Questões financeiras e de tempo, possivelmente, fizeram Cônego Trindade colocar os dois capítulos finais na mesma obra na qual ele pretendeu contar a história da Diocese de Goiás. Quanto a Poliantea, ficou como um livro apenas de homenagem, com fotos e textos elogiosos escritos por autoridades eclesiásticas.

Essa impressão vem da leitura do capítulo 39, "Influência social e política do padre secular nos destinos de Goiás". É um capítulo no qual ele faz um balanço, uma avaliação geral da participação do clero na história. No primeiro parágrafo do capítulo, seu autor escreveu: “[...] no término dessas crônicas[...]". Já no último parágrafo, ele diz "Finalmente, encerramos [...]" (1948, p. 435) e passa a tecer considerações conclusivas sobre a pesquisa feita para entregar ao público aquela "parcela mínima" de contribuição tanto para a Igreja quanto para o conhecimento histórico.

O título desse capítulo, que deveria ser o último no projeto original, é relevante para captar a situação em que o livro surgiu. Desde a separação oficial entre o catolicismo e o Estado brasileiro, a influência dos valores seculares era crescente. Verdade que o autor não vê com bons olhos o controle do imperador d. Pedro II sobre a Igreja. Isso é bem claro nos tópicos acerca da "questão religiosa" (1948, p. 240-268) e a prisão dos bispos. Mas, de qualquer modo, a "ímpia campanha anti-religiosa" continuou após o término daquela época de opressão estatal (1948, p. 267-8).

A cruzada contra as "idéias liberais" provinha de Roma. O Concílio Vaticano I (1869-1870) havia decretado uma pesada condenação ao mundo que surgia. Um pouco antes o Silabo dos erros (1864) proibiu, entre outras coisas, que a liberdade religiosa fosse defendida pelos católicos e que a moral fosse independente "da autoridade divina" (Bettenson, 1998, p. 378-380). O decréscimo do poder de influência eclesiástica, destarte, era vivenciado com pesar pelo clero.

2. Este capítulo no manuscrito é o de número 40, mas, como indicamos na introdução da reedição da obra (Silva, 2006), o capítulo XIII foi elidido na publicação. 
Sem o apoio estatal, a estratégia da Igreja Católica no Brasil seria reconquistar o espaço perdido por outros meios. A educação das elites passou a ser promovida pelas ordens européias, que multiplicaram sua presença rapidamente. Esses colégios católicos tentavam passar para os jovens os valores e as crenças do que Mainwaring (1989) denominou de neocristandade. ${ }^{3}$ Assim, uma nova economia teopolítica ${ }^{4}$ era buscada.

Se o Estado não era mais oficialmente cristão, a sociedade deveria ser. Além de trabalhar com a educação da juventude, os leigos adultos passaram a ter espaços de formação em movimentos como a Ação Católica. A figura do intelectual católico ganhou destaque social nessa época, tendo por tarefa articular, através da imprensa ou dos livros, a sua fé com as esferas cultural e política. Para Azzi, o resultado dessa produção foi eminentemente "reacionária" (1994, p. 105-129). Ressaltamos, contudo, que a plataforma dos movimentos "progressistas" que surgiram posteriormente foi idêntica, só a estratégia de reconquista mudou. ${ }^{5}$

Para recuperar o espaço público perdido, as grandes concentrações populares. Teve destaque a promoção em todo o país dos congressos eucarísticos. Como o nome indica, os católicos se reuniriam a partir de uma referência identitária importante: a doutrina da eucaristia. Ao mesmo tempo, a devoção eucarística dependia da presença clerical, reforçando o controle acerca do mundo popular. Os objetivos dessas manifestações, que incluíam as passeatas, eram tão religiosos quanto políticos. ${ }^{6}$

3. Para ele, o início deste "modelo de Igreja" foi a posse de d. Leme em Pernambuco, no ano de 1916, e a edição no mesmo ano de sua Carta Pastoral (1989, p. 41).

4. Com o conceito de teo-político queremos indicar a interdependência do crer com o poder. A manutenção do hífen simboliza, porém, o espaço de diferenciação que é mantido entre esses dois fenômenos. Se o Estado e a Igreja mantém alianças de interesses, cada um tem uma lógica própria e valores específicos.

5. Referimo-nos ao movimento que formulará, a partir dos anos 60, a Teologia da Libertação.

6. O primeiro congresso ocorreu na capital federal, em 1922. Assim Dias descreveu os objetivos do congresso: “em primeiro lugar [...] a restauração cristã do Brasil pela vida eucarística...; em segundo, [...] os temas mais polêmicos surgidos na relação entre Estado e Igreja [...]; em terceiro, vemos D. Leme fazendo o lançamento solene de sua plata-
O Congresso Eucarístico de Goiânia ocorreu em 1948, junto ao jubileu de d. Emanuel. Muitas autoridades eclesiásticas estiveram presentes. Como demonstrar a importância que tem o catolicismo para a população goiana se nem a catedral da capital estava concluída? ${ }^{7} \mathrm{~A}$ modernidade urbanística da cidade planejada não reforçava o aspecto secular? Goiânia não representava uma ruptura com as antigas tradições? Cônego Trindade defende que não se pode separar o catolicismo romano da própria formação do povo de Goiás. A influência social e política do clero foi imensa. O que foi feito e o que ocorrerá nessa história - um destino - tem como fundamento a rocha inabalável da fé católica.

\section{Um saber apologético}

Como um bom intelectual católico, Trindade é um apologeta da fé. Quer demonstrar as verdades que acredita e luta por elas. Cumpria periodicamente sua tarefa no jornal que dirigia, o Brasil Central. No livro, as armas são semelhantes, porém estão melhor escondidas.

Os periódicos explicitamente engajados em um causa ou uma corrente política eram comuns no Brasil desde o início do século XIX. A linguagem crua dos fatos não predominava ainda, prevalecendo o enfoque dissertativo e a exposição de opiniões (Buitorri, 2000, p. 59). Esse espaço logo será aproveitado também para a defesa das causas religiosas, tanto católicas como protestantes. Eram instrumentos modernos para a propaganda de suas visões de mundo. ${ }^{8}$ Através dessas publicações, as instituições reli-

forma político-pastoral [...]; por fim, [...] reivindicações dos direitos dos católicos para a constituição republicana e a campanha para a construção de um monumento em homenagem ao Cristo Redentor [...]" (1996, p. 109-110). Como se vê, tenta-se ampliar explicitamente os intercâmbios do campo teo-político.

7. A história da construção da catedral de Goiânia ainda está por ser feita. Ela aparece nos projetos iniciais da cidade e chegou a haver o lançamento da pedra fundamental na atual Praça do Cruzeiro. Não foi construída por quê? Quando a arquidiocese foi criada, em 1956, a antiga Igreja de Nossa Senhora Auxiliadora, que seria uma matriz provisória, terminou elevada a catedral.

8. Lembramos de que o termo propaganda, de origem religiosa, foi dicionarizado na língua portuguesa em 1858. Ainda nos faltam boas análises dessa utilização religiosa da imprensa. 
giosas adequavam-se ao ritmo da novidade, da informação rápida típica da modernidade.

A Diocese de Goiás começou a publicar seus jornais no início do século XX. O mais antigo que identificamos foi $O$ Lidador, editado em Uberaba, que começou a circular em janeiro de 1903. Conforme Cônego Trindade, foi produzido durante quinze anos (1948, p. 379). O segundo jornal, o Brasil Central, foi criado em 1931. Nas palavras do mesmo sacerdote, esse periódico constituía "uma sentinela vanguardeira da causa católica" (1948, p. 468).

Os artigos desses jornais têm um compromisso com a verdade, mas assumem com maior clareza seu viés interpretativo. A linguagem informativa não apaga a subjetividade das análises. Com o livro de história é diferente. $\mathrm{O}$ método de erudição crítico igualmente surge com a modernidade. Entretanto, ele pretende ser puramente objetivo, aproximando-se do conhecimento científico e do saber acadêmico. Os fatos deveriam ser narrados sine ira et studio. Essa foi a grande busca da historiografia que, hoje, denominamos metódica (Bourdé e Martin, 1990, p. 97ss).

Do mesmo modo que fazia nos jornais, Trindade usou de um instrumento moderno para defender as opiniões a que tinha apreço. A objetividade postulada pelo método histórico seguido não atrapalhava os objetivos mais profundos que tinha com a obra? Como defender o catolicismo e ser imparcial?

Eis o cerne da questão. A resposta pode vir refletindo sobre a abordagem de um colega religioso do mesmo período: padre Serafim Leite. Ele escreveu uma imensa obra histórica. Entre outras, os dez volumes da História da Companhia de Jesus na província do Brasil (19381949). Na introdução desse monumento de erudição, o dogma da imparcialidade e o fascínio do nível factual:

Que faz o historiador? Pega nos documentos e inicia sistematicamente a redistribuição necessária atribuindo a diversas pessoas e lugares os fatos [...]. (1938-1949, p. XVI, grifo nosso)

A história científica é, e há de ser sempre, as datas e homens, com a sua múltipla atividade no tempo e no espaço. Mediante investigação rigorosa, procura desprender de tudo, com nitidez, a linha geral dos acontecimentos. (19381949, p. XVII)

Cônego Trindade não descreveu seu método, mas cremos que assinaria embaixo dessas linhas. Era a receita da época para fazer uma história de qualidade. Encontramos, inclusive, uma expressão semelhante à do título dado pelo sacerdote goiano a seu livro.

O rigor investigativo promulgado não impede o coração de se manifestar. Nas quase quatro mil páginas da obra de Serafim Leite, a defesa dos jesuítas é incessante e muitas vezes ele os descreve como verdadeiros heróis. Para exemplificar a expressão das crenças subjetivas do autor, podemos nos referir ao último capítulo do tomo VII, no qual ele descreve o processo de expulsão da Companhia de Jesus nos meados do século XVIII. A santa ira ali é claramente manifesta contra os atos do primeiro-ministro Marquês de Pombal.

As categorias de leitura documental utilizadas na construção do livro Lugares e pessoas é semelhante. $\mathrm{O}$ apego às fontes históricas esbarra no amor à Igreja. Os documentos que indicam o despreparo do clero no século XIX seriam "casos isolados" (1948, p. 180). As inúmeras irregularidades na vida sacerdotal e o descumprimento dos votos não devem ser recriminados, pois eram coisas do período. Também eram conseqüência de uma terra recém-saída da barbárie. Até o regime do padroado o autor invoca para explicar esse tipo de comportamento, compensado amplamente pelo caráter dos varões dedicados que trabalharam em Goiás (1948, p. 299).

Documentos "detratadores" ele contorna. Contudo, apesar de sua aversão às longas citações (1948, p. 21), ele as utiliza abundantemente quando o assunto é de seu interesse. $\mathrm{O}$ maior exemplo no livro são os trechos nos quais trata da maçonaria. No jornal Brasil Central até identificados com os comunistas os maçons são. ${ }^{9} \mathrm{Na}$ obra histórica, Trindade prefere utilizar o magistério eclesiástico para demonstrar que "a maçonaria é uma seita inimiga da Religião

9. Conferir o número publicado em 30 de novembro de 1937, página 4 . 
Cristã" (1948, p. 242). Vários documentos se seguirão com o mesmo teor. Na conclusão, ele se justifica, afirmando que o tema o "forçou" a prolongar as diversas transcrições (1948, p. 267).

Que força superior seria essa? Parece-nos que ele se tornou prisioneiro do próprio lugar que ocupa. O sacerdócio fala, portanto, mais alto. Trindade concorda com Pascal, tanto no diagnóstico como na solução: a Verdade do catolicismo é imbatível. O saber histórico a serve como, anteriormente, a filosofia servia à teologia.

\section{Um saber teológico}

Isso ocorre, de maneira paradoxal, devido à secularização. Tal conceito, que já foi chave no entendimento das especificidades do mundo ocidental, tem gerado muita polêmica e discussão nos últimos anos. Um exemplo significativo da mudança ocorrida pode ser dado nas análises de Peter Berger. Ele já foi um dos árduos defensores da teoria acerca do processo cultural secularizador, tendo essa idéia como condição sine qua non de qualquer estudo da religião na modernidade (1985). ${ }^{10}$ Trinta anos depois, propunha a "dessecularização" do enfoque teórico, afirmando que muitas "comunidades religiosas sobreviveram e até floresceram na medida em que não tentaram se adaptar às supostas exigências de um mundo secularizado" (2001, p. 11, grifo nosso).

Em que pese o debate corrente, seria difícil negar o duradouro movimento de decréscimo do poder de influência da religião, particularmente no espaço público. Já falamos em secularização seletiva (Quadros, 2005) na tentativa de entender essa retomada do crescimento das instituições religiosas a partir dos anos 70. Com o termo, queríamos apontar que um dos graves problemas das teorias acerca do fenômeno eram a linearidade e a inexorabilidade implícitas nelas. Os deuses, afinal, não morrem;

\footnotetext{
10. A publicação dessa obra em inglês data de 1969. Nela, Berger defende que o específico do capitalismo ocidental foi ter gerado a secularização e o conseqüente pluralismo religioso, precondição do funcionamento das instituições religiosas. Daí, "a crise de credibilidade" e de "plausibilidade" das mensagens baseadas na fé (1985, p. 139ss).
}

vão habitar outros espaços. Sua absoluta soberania, porém, foi colocada em xeque.

Esse rearranjo topológico da fé, como vimos, foi claramente percebido pela hierarquia católica no início do século passado. Uma estratégia elaborada foi a ênfase nas "raízes cristãs" da cultura ocidental. No Brasil, todo um movimento intelectual abraçou essa perspectiva, seguindo próximo do que afirmaram os bispos durante as comemorações do Centenário da Independência:

\begin{abstract}
Se procurarmos fazer renascer o nosso passado, se reconstruirmos a nossa vida colonial ou consultarmos os períodos mais fecundos da nossa vida intelectual, a ciência e as artes, a história e a legenda, a poesia e a eloqüência, as festas e as canções populares nos mostram a Igreja presente em toda a parte agindo sempre para o bem do Brasil, tanto nos dias de júbilo como nos dias de tristeza, na guerra como na paz. (Apud Azzi, 1994, p. 46)
\end{abstract}

Dessa agenda partiu Cônego Trindade, contextualizando tais princípios em Goiás. Os lugares do estado estariam marcados sobejamente pela cruz. Nas suas palavras, os padres exerceram o papel de "verdadeiros bandeirantes de Deus" (1948, p. 426), sendo os maiores construtores dos "fundamentos cristãos que firmaram a nossa nacionalidade" (1948, p. 424). Em sua época, todavia, aquela virtuosa história estava sendo esquecida e desvalorizada. Sua escrita histórica estava a serviço do resgate dessa memória.

Mas não apenas isso. Além de demonstrar a importância da ação eclesiástica na constituição de Goiás, há um processo de tradução doutrinária. A questão que inicialmente para o autor seria relembrar o papel da Igreja metamorfoseia-se no ato de falar da fé. Como fazê-lo em um ambiente secularizado? Como convencer o mundo intelectual daquelas verdades? Através da utilização de uma linguagem histórica.

$\mathrm{O}$ arcabouço científico é respeitado, pois constitui o grande regime de verdade articulado na modernidade. O discurso histórico estava plenamente legitimado, inclusive pelo universo acadêmico. Ele será uma bela roupagem para o avariado saber teológico. 
Este, no Brasil, fora excluído do ambiente universitário. Nossa tradição cultural positivista o colocara como algo infantil, um tema a ser evitado. ${ }^{11}$ Já na Europa e nos Estados Unidos, a teologia conseguiu permanecer na academia, mesmo que para isso tenha assumido características de um conhecimento objetivo. Dois casos são significativos: os estudos bíblicos e as chamadas ciências da religião.

Não é o caso aqui de desenvolver uma longa análise acerca dos dois. Para nossos propósitos, basta apontar o papel relevante do conhecimento histórico em ambos. Na crítica bíblica, desde os finais do século XVIII, a investigação histórica constitui o principal eixo da cientificidade das abordagens. O contexto passa, então, a determinar o conteúdo dos textos e seu grau de veracidade (cf. Tillich, 1986). Já nas ciências da religião, os dados históricos foram considerados tão importantes em suas diversas áreas que o grupo organizado para congregar diversas instituições de pesquisa fora denominado de International Association of the History of Religions, tendo sua assembléia recusado várias vezes a retirada do termo história da denominação (Filoramo e Prandi, 1999, p. 14). ${ }^{12}$

Destarte, a secularização manifesta-se tanto na conjuntura quanto na estrutura da obra. Esse fenômeno motivou os estudos históricos de Cônego Trindade e está presente no tipo de abordagem por ele escolhida. Constitui ainda o alvo da pesquisa, só que sob expoente negativo: era algo a ser vencido.

\section{Um saber antimoderno}

Há um curto-circuito no texto. Uma expressão da modernidade surge como arma para derrubá-la. Se não totalmente, ao menos em uma tentativa de atenuar o processo secularizador. A pretensão do autor é, assim, assegurar o lugar proeminente das pessoas que formam a Igreja. Isso se torna explícito na sua forma de conceber a história eclesiástica.

11. Um dossiê sobre o tema encontra-se no livro Sociologia da religião no Brasil (Souza, 1998).

12. O mesmo aconteceu no Brasil, com a criação da Associação Brasileira de História das Religiões, em 1999.
Mesmo com a intenção de demonstrar a fé católica do povo goiano, sua obra está bem distante de um projeto de história "popular". Cônego Trindade aproxima-se da historiografia religiosa como fora produzida por Euzébio de Cesaréia (1989) no século V d.C., época da constituição da cristandade no Ocidente. $\mathrm{Na}$ análise desse último historiador feita por Eduardo Hoornaert, os paralelos encontrados são muitos.

Primeiro, a ênfase documental, incluindo a série de transcrições das fontes (Hoornaert, 1986, p. 24). Já vimos que, na época do cônego, essa tendência foi reforçada pela concepção epistêmica da historiografia metódica e cientificista. Em segundo lugar, temos a aproximação e o elogio do Estado (1986, p. 26). Em Lugares e pessoas, é verdade, tal relação não é linear. Trindade critica fortemente o direito régio ao padroado (1948, p. 145). Mas isso ocorre porque a Igreja, em sua visão, ficava submetida aos poderes estatais. O correto seria o inverso: a "Divina Religião Católica Apostólica Romana" é que deveria governar o Estado (1948, p. 240). Daí intitular a Constituição de 1891, que separou administrativamente as duas instituições, de "constituição agnóstica" (1948, p. 320).

$\mathrm{O}$ terceiro ponto em comum encontra-se na concepção de Igreja. Ela está resumida ao clero, com destaque para o episcopado (Hoornaert, 1986, p. 26). No caso do Cônego, desde que o primeiro bispo instala-se em território goiano, durante o ano de 1824, eles ocupam o centro semântico das descrições. O relato minucioso das ações episcopais e as diversas transcrições dos documentos que produziram comprovam-no. Em um segundo nível vêm os padres. Por motivos cronológicos, os primeiros a serem citados são os com vocação religiosa, mas, em acordo com seu próprio estado, a obra dos padres seculares será destacada pelo autor. Somente no terceiro nível semântico vêm os católicos leigos. Imbuído dos valores da romanização, Cônego Trindade não costuma considerá-los bons católicos. Podem dar um exemplo ou outro de fidelidade à Igreja, predominando, todavia, a representação negativa tanto de suas crenças como de seus atos. As religiosas, um possível quarto nível cristão, surgem apenas de maneira esporádica nessa história. Tal organi- 
zação hierárquica do mundo histórico expressa a cosmovisão religiosa resultante do Concílio Vaticano I.

Mais um ponto de interseção entre os dois autores advém das oposições que norteiam a narrativa. Conforme Hoornaert, Euzébio de Cesaréia colocou como eixos os pólos entre perseguição e vitória, opressão e liberdade, ortodoxia e heresia (1986, p. 25). Na obra de Trindade, eles também se evidenciam. Exemplos podem ser facilmente encontrados nos capítulos acerca do conflituoso episcopado de d. Eduardo (1948, p. 332-357). Citamos aqui apenas as primeiras linhas do capítulo no qual o autor trata da mudança da sede episcopal de Goiás para Uberaba:

As lutas políticas travadas na cidade episcopal de Goiás atingiram a um clima insuportável. O pobre bispo, sempre alheio a qualquer partidarismo, acabou por sofrer, na sua administração tão fecunda e bem intencionada, as conseqüências desastrosas dessa campanha. (Silva, 1948, p. 347)

O bispo está sempre certo em suas decisões, representando a ortodoxia sem partidarismo. Seu grande esforço para purificar a fé, contudo, é prejudicado pela oposição que sofre de políticos hereges. D. Eduardo está, destarte, correto em libertar a santa Igreja da opressão vivida em Goiás. Sua perseguição será compensada pelas vitórias obtidas na nova sede, "mostrando ao Brasil o valor de sua capacidade de realizar e administrar" (1948, p. 356).

Há um tópico na obra de Euzébio de Cesaréia que Hoornaert não destacou, mas que surge de maneira semelhante no livro de Trindade. É a concepção providencialista da história. Por muitos séculos, a teologia cristã defendera a crença de ser Deus quem guia a história, utilizando para isso a vontade dos homens.

Não de qualquer homem. São grandes homens que fazem a história. Eles agem, a princípio, por si, pela própria vontade e por determinação. Nesse nível empírico, a consciência funcionaria como o motor da história. Por isso, não encontramos no livro interpretações com viés mais sociológico ou análises do campo de forças em que os sujeitos estão inseridos. Predomina a interpretação heroicizante dos personagens históricos e, tratando-se do clero, uma leitura quase hagiográfica.

Cônego Trindade permanece, entretanto, coerente com o método histórico adotado. Ele não invoca gratuitamente a providência para explicar as transformações da história. Os arroubos teológicos são bastante contidos em seu texto. Porém, a nosso ver, a perspectiva providencialista está sempre implícita. Deus está atuando através da Igreja, que, por sua vez, consagra a história humana. Ou seja, como ele mesmo diz, podemos escutar "a justiça de Deus na voz da história” (1948, p. 268).

Assim, chegamos a uma compreensão melhor do subtítulo da obra. Ele expressa a idéia de que a Igreja é o ponto de apoio (sub-sidium), o fundamento ordenador das mudanças nas sociedades humanas. É nela que pode ser encontrada a verdadeira história dos homens, conseqüentemente de Goiás. Os grandes homens a realizaram somente na posição de instrumentos da majestática vontade divina.

Rejeitando a unificação das histórias sagrada e profana, pondo a primeira acima da última, Trindade torna-se incapaz de incorporar plenamente a concepção científica da investigação do passado. Ele atinge o limite dado por seu lugar. Essa fissura, ele tenta repetidamente costurar com os eventos da narrativa. Mas as distâncias a cruzar não seriam demasiadamente grandes?

\section{Considerações finais}

O disfarce da imparcialidade, como vimos, serviu para muitos usos. O princípio da cientificidade foi transformado em uma astúcia discursiva para manifestar um elemento eminentemente pessoal: a fé. Isso não decorre da incompetência de Cônego Trindade ou dos juízos impressionistas que incutiu na obra. Não é um defeito particularizado em Lugares e pessoas, mas algo inerente à pretensão incorporada pelas ciências humanas de descrever a realidade desinteressadamente.

Habermas demonstrou de forma clara como o ato de conhecer está intimamente ligado ao interesse. $\mathrm{O}$ interesse da razão coaduna-se ao 
nosso interesse próprio (Habermas, 1987, p. 226). Tal assertiva seria válida tanto para as "ciências empírico-analíticas" quanto para as "ciências hermenêuticas". Estas últimas teriam, contudo, uma particularidade, devido à identidade do sujeito com o objeto do saber. Então, na conclusão do livro, o pensador alemão toma por modelo epistemológico a obra freudiana. A autoreflexão seria uma técnica importante para os pesquisadores atingirem um conhecimento mais congruente (1987, p. 308ss).

Não discordamos da relevância de um método reflexivo para as ciências humanas. Contudo, consideramos tal solução ainda precária. Essa seria, aliás, uma resposta idealista a surgir inesperadamente na pena de alguém que já pretendeu reconstruir o materialismo histórico (Habermas, 1996). A consciência do lugar social ocupado de maneira nenhuma neutraliza esse lugar. A busca de falar de lugar nenhum remonta, inclusive, aos paralelos recorrentes entre a ciência e o sacerdócio, ambos encarados como missão por Cônego Trindade.

As pessoas ocupam, portanto, lugares discursivos, quer queiram, quer não queiram. A historiografia não foge à regra, como demonstrou Michel de Certeau (1981). ${ }^{13}$ Esse lugar deve ser compreendido como uma vitória do tempo sobre o espaço, uma concentração histórica presente em todo dizer do saber.

Cônego Trindade queria o contrário: abstrair-se da história. Ele buscou no passado as marcas do que permanece, do que não muda, do Eterno. Adere à operação, igualmente realizada pela historiografia nacionalista, de elevar o discurso histórico a saber mítico. Um mito travestido pelo belo tailleur científico.

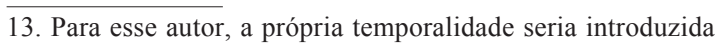
por uma "dialética dos lugares", "porque existe tempo lá onde uma dinâmica de lugares (places) diferentes não é superada por um nenhum dentre eles. [...] Interrogar o sujeito do saber é, aliás, ter que pensar sobre o tempo, se é verdade que o sujeito se organiza como uma estratificação de tempos heterogêneos e que - mulheres, negros ou judeus - ele é estruturado por sua relação com o outro. O tempo é precisamente a impossibilidade de se identificar ao lugar (lieu)" (Certeau, 1981, p. 124). Fica claro que as idéias certeaunianas foram a principal base teórica deste artigo.
Abstract: The book Places and people, wrote by José Trindade da Fonseca e Silva, has been published sixty years ago. Although, it continues being the great synthesis about the history of the church in the state of Goiás. In this article, we analyze this book, pointing how historical knowledge worked as a platform to ecclesiastical combats lived by the author.

Key-words: Church; historiography; science; secularization; faith.

\section{Referências}

ALENCASTRE, José M. P. de. Anais da província de Goiás (1863). Goiânia: Sudeco, 1979.

AZZI, Riolando. A neocristandade: um projeto restaurador. São Paulo: Paulus, 1994.

BERGER, Peter. O dossel sagrado: elementos para uma teoria sociológica da religião. São Paulo: Paulinas, 1985.

- A dessecularização do mundo: uma visão global. Religião e Sociedade, 21(1), abril de 2001, p. 9-24.

BETTENSON, H. Documentos da Igreja Cristã. São Paulo: Aste, 1998.

BOURDÉ, G; MARTIN, H. As escolas históricas. Lisboa: Publicações Europa-América, 1990.

BUITORRI, Dulcinéia H. S. Entre o consumo rápido e a permanência: jornalismo de arte e cultura. In: MARTINS, Maria Helena (Org.). Outras leituras. São Paulo: Editora do Senac, 2000. p.57-72.

CERTEAU, Michel de. L'histoire dans une politique de la science. Espirit, 10-11, oct-nov 1981. p. 120129.

. A escrita da história. Rio de Janeiro: Forense Universitária, 1982.

Heterologies - Discourses on the other. Minneapolis: University of Minesota press, 1997.

CESARÉIA, Eusebius de. The history of the church. London: Peguin Books, 1989.

DELACROIX, Christian et alli. Michel de Certeau: Les chemins d'histoire. Paris: Editions Complexe, 2002.

DIAS, Romualdo. Imagens da ordem: A doutrina católica sobre a autoridade no Brasil. São Paulo: Editora da Unesp, 1996.

FILORAMO, G; PRANDI, C. As ciências da religião. São Paulo: Paulus, 1999.

HABERMAS, Jurgen. Conhecimento e interesse. Rio de Janeiro: Guanabara, 1987.

. Reconstrucción del materialismo histórico.

Madrid: Taurus, 1996. 
HARTOG, François (Ed.). A história de Homero a Santo Agostinho. Belo Horizonte: Editora UFMG, 2001.

HOORNAERT, Eduardo. A memória do povo cristão. Petrópolis, RJ: Vozes, 1986.

LEITE, Pe. Serafim. História da Companhia de Jesus na Província do Brasil. Rio de Janeiro: Instituto Nacional do Livro, 1938-1949.

MAINWARING, Scott. Igreja Católica e política no Brasil. São Paulo: Brasiliense, 1989.

QUADROS, Eduardo Gusmão. O "pequeno deus" do mercado religioso brasileiro. In: SCHIAVO, Luigi (Org.). Mística e pós-modernidade. Goiânia: Editora da UCG, 2005. p. 67-82.
SILVA, José Trindade da Fonseca e. Lugares e pessoas - Subsídios eclesiásticos para a história de Goiás. São Paulo: Escolas Profissionais Salesianas, 1948.

SILVA, Cônego José Trindade da Fonseca e. Lugares e pessoas - Subsídios eclesiásticos para a história de Goiás. 2. ed. Goiânia: Editora da UCG, 2006. [No prelo].

PASCAL, Blaise. Pensamentos. Rio de Janeiro: Athena editora, 1946.

SOUZA, Beatriz M. et alli. Sociologia da religião no Brasil. São Paulo: PUC/Umesp, 1998.

TILLICH, Paul. Perspectivas da teologia protestante nos séculos XIX e XX. São Paulo: Aste, 1986. 